\title{
Improving the Reliability of Fishery Predictions Under Climate Change
}

\author{
Keith Brander
}

Published online: 3 February 2015

(C) Springer International Publishing AG 2015

\begin{abstract}
The increasing number of publications assessing impacts of climate change on marine ecosystems and fisheries attests to rising scientific and public interest. A selection of recent papers, dealing more with biological than social and economic aspects, is reviewed here, with particular attention to the reliability of projections of climate impacts on future fishery yields. The 2014 Intergovernmental Panel on Climate Change (IPCC) report expresses high confidence in projections that mid- and high-latitude fish catch potential will increase by 2050 and medium confidence that low-latitude catch potential will decline. These levels of confidence seem unwarranted, since many processes are either absent from or poorly represented in the models used, data are sparse and, unlike terrestrial crop projections, there are no controlled experiments. This review discusses methodological issues that affect our understanding of climate impacts, such as how to improve coupled models from physics to fish and how to strengthen confidence in analysis of time series.
\end{abstract}

Keywords Climate · Fisheries · IPCC · Global models . Fishery potential $\cdot$ Fish distribution $\cdot$ Temperature impacts . Adaptation $\cdot$ Recruitment $\cdot$ Spatial dynamics $\cdot$ Regional impacts $\cdot$ Marine ecosystems $\cdot$ Fishery management

\section{Introduction}

Recent research into the impacts of climate change on fisheries has been given impetus by a number of questions of both

This article is part of the Topical Collection on Ecological Impacts of Climate Change

K. Brander $(\bowtie)$

National Institute of Aquatic Resources, Technical University of Denmark, Copenhagen, Denmark

e-mail: kbr@aqua.dtu.dk scientific and societal interest: How is future global and regional fishery potential likely to change? What are the uncertainties underlying projections of future catch potential and how can uncertainties be reduced? Are observed fish distribution changes due to climate or are there other drivers? Can fish adapt or acclimatise to changing conditions? How should fishery management and fishing enterprises adapt? What are the economic and social consequences and where is vulnerability high? These questions are addressed in recent papers that are introduced here, including the Intergovernmental Panel on Climate Change (IPCC) Fifth Assessment Report. Readers should refer to the cited papers for details and fuller answers than can be given in a short review.

A review of new literature on the impacts of climate change on fisheries has to begin by deciding how to delimit and organise the large and diverse body of material. Papers on climate, marine ecosystems, fish population dynamics and fisheries are relevant and may include observations, experiments, theory, modelling, statistics, economics, social studies, history, policy and management. The aims of this review are to assemble new evidence of regional and global impacts; to present advances in methodology and process understanding; to introduce current analyses, models and projections of the state of fisheries under climate change; and to evaluate consequent advice on policy, adaptation, management and research priorities.

Interest in the topic has been rising sharply, with the number of publications doubling every five years since 1990 [1], and this interest is not confined to the scientific community. Some of the scientific papers introduced here have been reported and discussed in public media (e.g. The Economist 31 March 2014, Apocalyptish and 5 April 2014, In the balance). Fishery enterprises, supermarket buyers, policy makers, NGOs and the general public learn from these sources about climate impacts, and this stimulates public and political concern over the current and future state of marine ecosystems, fisheries and food supply. 


\section{Impacts of Climate on Fisheries in the IPCC Fifth Report 2014}

The recently published IPCC report on Impacts, Adaptation and Vulnerability http://ipcc.ch/report/ar5/wg2/ provides both an up-to-date synthesis of our knowledge of climate impacts on marine systems and a widely reported presentation of key findings in relation to fisheries (Chapter 6 Executive Summary):

By the mid-21st century, the spatial shifts of marine species will cause species richness to increase at midand high latitudes (high confidence) and to decrease at tropical latitudes (medium confidence), resulting in global redistribution of catch potential for fishes and invertebrates, with implications for food security (medium confidence). Animal displacements are projected to lead to high-latitude invasions and high local-extinction rates in the tropics and semi-enclosed seas. This will cause a $30-70 \%$ increase in the fisheries yield of some high-latitude regions by 2055 (relative to 2005), a redistribution at mid latitudes, but a drop of $40-60 \%$ in the tropics and the Antarctic, based on $2{ }^{\circ} \mathrm{C}$ warming above pre-industrial values (medium confidence in the direction of trends in fisheries yields, low confidence in the magnitude of change). If a decrease in global net primary production (NPP) or a shift towards smaller primary producers occurs, the overall fisheries catch potential may also decrease.

The basis for, and reliability of, such projections can be evaluated from papers introduced in the present review. The IPCC report is not easy to follow, and there are contradictions within Chapter 6 and with other chapters that speak to the complexity and uncertainty of the underlying science. Projections are of necessity conditional, as exemplified by the last sentence of the above key finding. A map (Fig. 1 [2]) showing redistribution of world fish catch potential by 2055 has been used extensively in world media (e.g. http://www.bbc.com/ news/science-environment-26814742). The spatial resolution and nine colour gradations may give a more confident impression of our ability to make such projections than is warranted by the actual state of knowledge, especially when, as is often the case, the conditions and confidence statements in the IPCC report are omitted in subsequent presentations.

The IPCC Synthesis Report (http://ipcc.ch/pdf/assessmentreport/ar5/syr/SYR_AR5_LONGERREPORT.pdf), adopted on 1 November 2014, ascribes high confidence to the projections of changes in species richness and fishery catch potential at high and mid latitudes, despite mentioning that the effects of future primary production, ocean acidification, oxygen and disruption of trophic structures are not included in this projection and that it is based on a single climate model. For comparison, projections of future yields of wheat, rice and maize are assigned medium confidence by the IPCC based on highly replicated controlled experiments and 1090 data points from crop model projections covering different emission scenarios, tropical and temperate regions and adaptation and no-adaptation cases.

\section{Regional and Global "End-to-End" Models}

A generic structure diagram of a coupled end-to-end physicalbiogeochemical-ecosystem model (Fig. $2[3 \cdot \bullet]$ ) indicates where major uncertainties arise due to (i) input data, (ii) model uncertainty and (iii) observational data used for parameterisation and model testing. Evans et al. [3••] caution against models that do not present all the uncertainties and propagate these uncertainties clearly and completely into the eventual management advice [4]. Since full understanding and certainty about such complex systems is unattainable, the goal must be to develop advice and management that is robust to unavoidable uncertainty. Management Strategy Evaluation is an empirical approach that can be used to explore the robustness of alternative strategies to changing biological parameters [5]. Management strategies based on such empirical
Fig. 1 Projected global redistribution of maximum catch potential (average for 2015-2060 relative to 2001-2010) (from Cheung [2] redrawn for Chapter 6 of the IPCC report)

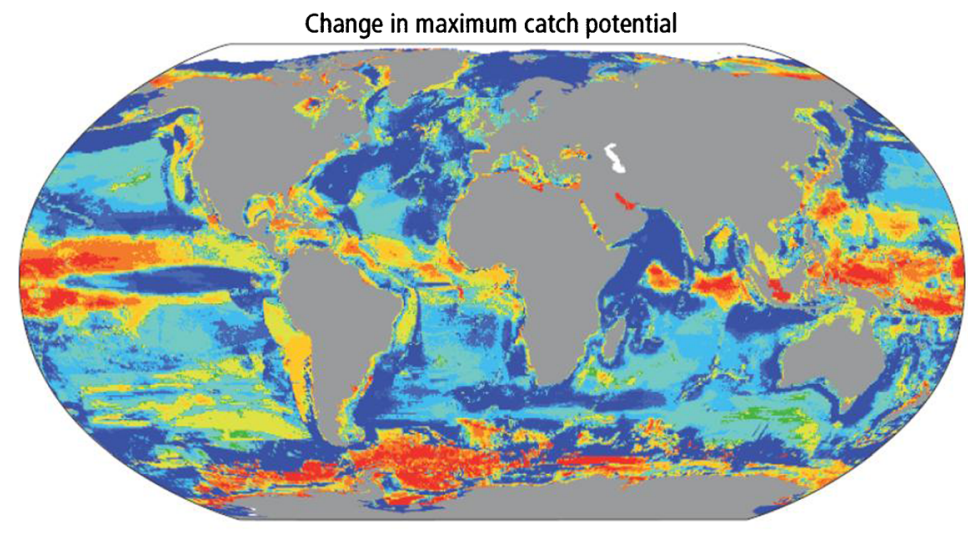




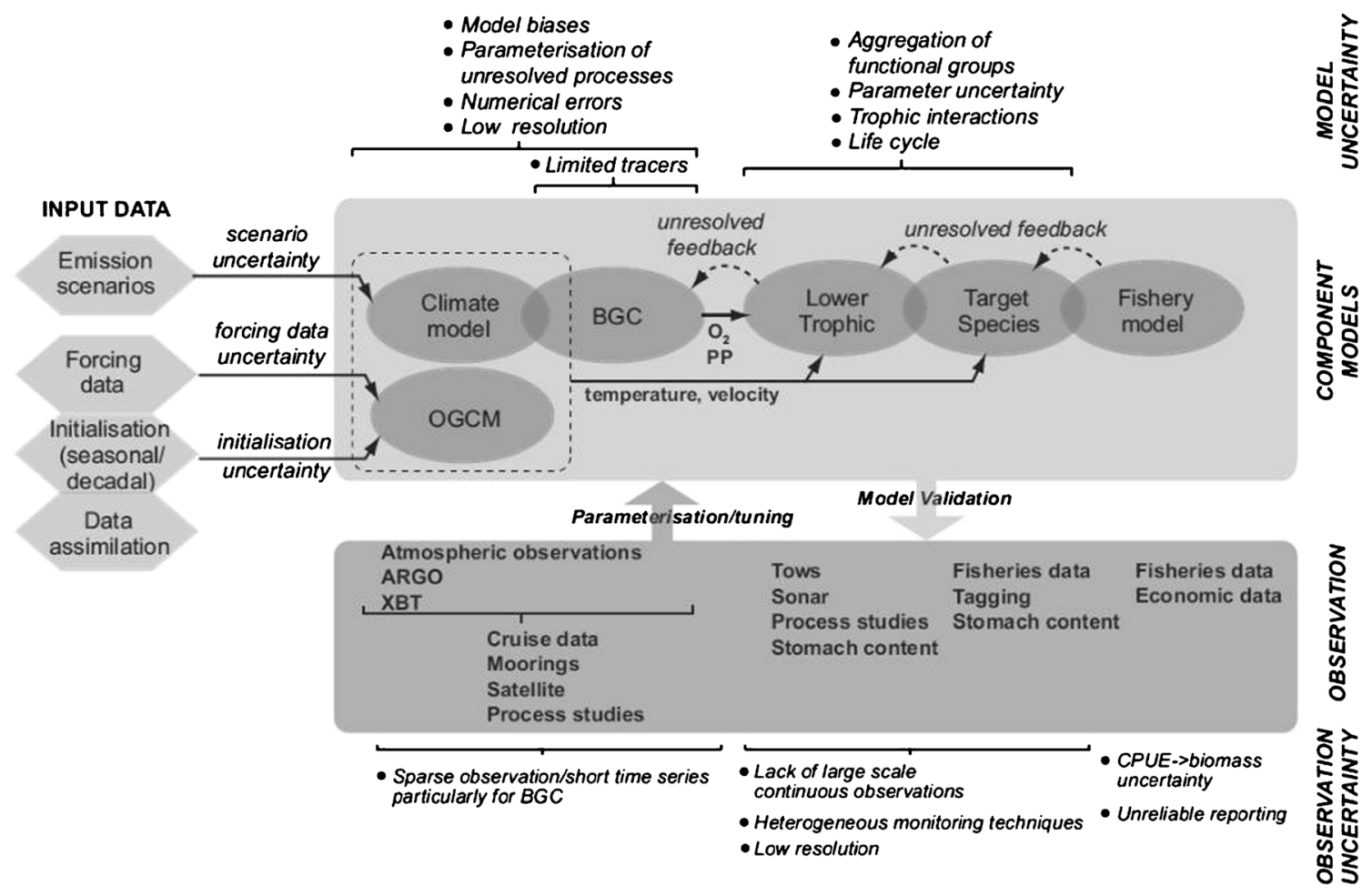

Fig. 2 Components of an end-to-end physical-biogeochemical-ecosystem modelling framework. Uncertainties in italics. OGCM ocean general circulation model, $B G C$ biogeochemistry, $P P$ primary productivity,

evaluations are likely to outperform strategies that rely on uncertain predictive modelling [5], and management systems that are able to respond rapidly to climate-induced changes are likely to be more effective in preventing stock decline.

Few coupled end-to-end models have been used to date to project changes in regional $[6 \bullet \bullet, 7-9]$ and global $[10 \bullet, 11 \bullet \bullet]$ fisheries, and, unsurprisingly for a new type of model, much of the discussion in those papers is about methodology, architecture, processes, validation, intercomparison and uncertainty. Blanchard $[10 \bullet \cdot$ and Barange $[11 \bullet \bullet$ ] extend a highresolution end-to-end model that was developed for the NW European Shelf to cover all coastal oceans. They project declines of 30-60\% in potential fish production (in 2050 relative to 1992-2001) for many tropical shelf and upwelling seas, most notably in the eastern Indo-Pacific, the northern Humboldt and the north Canary Current. For some high-latitude shelf seas, they project increases of $28-89 \%$. Most of the world fishery production comes from coastal and shelf areas, and the current generation of global models does not resolve important processes in shelf sea ecosystems (e.g. tides, wind, run-off, recycling, seasonal stratification). Other processes may also affect projections; for example, ocean acidification [12] and lower oxygen levels may reduce growth and hence future catch potentials in the NE Atlantic [6••]. Some areas (e.g. Iceland, Norwegian Sea) where large increases in catch potential had been predicted (Fig. 1) may instead experience decreases due to sensitive responses to lower $\mathrm{pH}$ and oxygen.
$A R G O$ array for real-time geostrophic oceanography, $X B T$ expendable bathythermograph, $C P U E$ catch per unit effort

The sensitivity of five taxa (corals, molluscs, echinoderms, crustaceans and fish) to levels of acidification that are likely to occur later this century suggests that substantial change and reorganisation of marine ecosystems will result [13]. Fish exhibit considerable interspecific variability in sensitivity, which would result in winners and losers under increased acidification; however, evidence is limited and may be affected by publication bias, if experiments not showing an effect are less likely to be published.

Decline in average size of phytoplankton could further reduce future catch potential by $\sim 10 \%[6 \bullet \bullet$. Hollowed et al. [14 $\bullet]$ compare different types of coupled end-to-end models and conclude that the necessary structure and complexity depend on the kind of question they are intended to address. Hollowed and others [9, 15] strongly support the need for adequate monitoring of marine systems and for conducting empirical and modelling analyses in parallel.

\section{Global Rates of Temperature Change and Observed Impacts}

Changes in ocean $\mathrm{pH}$, oxygen, mixing processes and other climate-related variables all affect marine biota, but temperature is the major and most easily measured factor affecting individual and population growth rates, distribution and phenology. A global analysis of geographic shifts in isotherms of 
sea surface temperature (SST) and of seasonal timing of warming and cooling over the past 50 years $[16,17]$ has been used to test whether observed geographic and phenological shifts in biota match the rates of shift in temperature. Using the first large global database of the distributional and phenological responses of marine biota, Poloczanska [18••] found that $81-83 \%$ of all observations for distribution, phenology, community composition, abundance, demography and calcification across taxa and ocean basins were consistent with the expected impacts of climate change. Rates of distribution shifts were, on average, consistent with rates of surface temperature shift, but there was no consistent relationship between regional shifts in spring phenology and the seasonality of temperature change.

The average rate at which the leading edges of marine species distributions, particularly plankton and fish, have expanded is much faster than rates reported for terrestrial species (72 and $6.1 \mathrm{~km} \mathrm{dec}^{-1}$, respectively) and also much faster than the average rate of marine trailing edge contraction $\left(15.4 \mathrm{~km} \mathrm{dec}^{-1}\right)$. This finding is somewhat at odds with another study [19] that finds similar rates of shift at leading and trailing edges, and the reasons for the difference may be that our observational base is still very limited or that it is explained by regional temperature differences. Nevertheless, observational studies confirm that ocean temperature changes have affected marine biota and provide strong evidence of anthropogenic climate impacts, since a substantial component of ocean warming is of anthropogenic origin. The signature of ocean warming has been detected in global fish catches, by using an index of the mean temperature of the catch [20].

\section{Modelling and Observation of Global Lower Trophic Levels}

The quality of physical, biogeochemical and lower trophic level modelling is critically important for credible modelling of upper trophic levels and fisheries [21••]. Global simulations indicate a decrease in primary production of around $9 \%$ and in zooplankton biomass by $11 \%$ (2080-2100 relative to 1980-2000 under A1B scenario [22]). There is substantial regional variability, with increases in primary production expected in some areas (Barents Sea, Baltic Sea, Black Sea) and declines in others (Benguela, North Sea). However, another feature of the simulations is that, as indicated by the relatively greater decrease in zooplankton compared with phytoplankton, some degree of negative trophic amplification (i.e. decline in average trophic transfer efficiency) is expected across $47 \%$ of the ocean surface (Fig. 3). Zooplankton models are currently not as well founded as those for phytoplankton, or indeed fish, with several important issues, including food selectivity, kinetics of prey consumption,

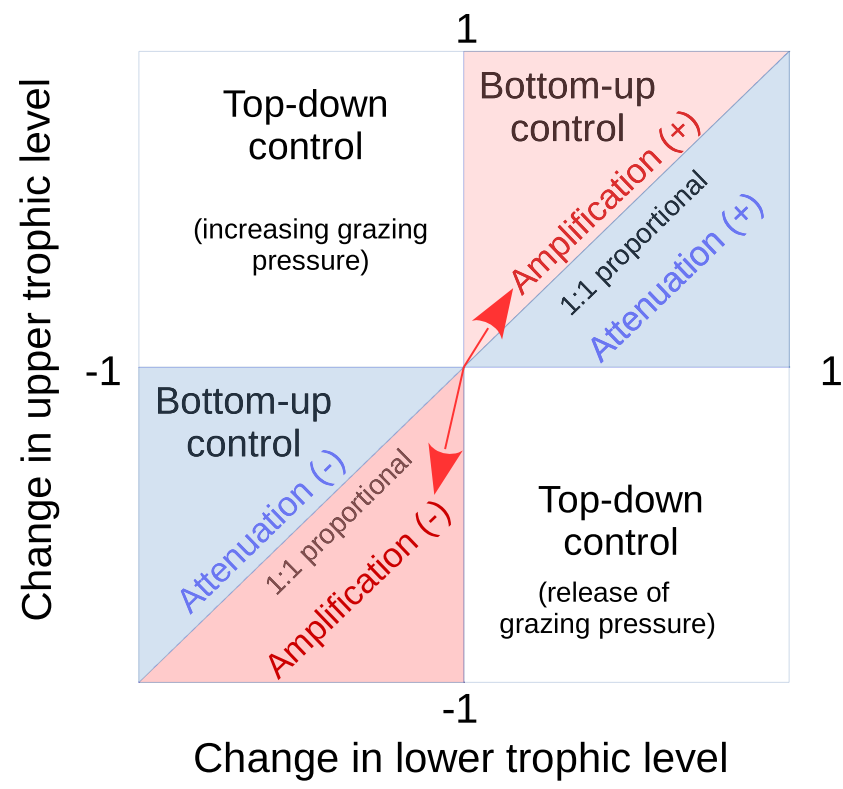

Fig. 3 Trophic amplification

interactions with assimilation and growth, form of voided material and mortality rates requiring further experimental and modelling investigation $[21 \bullet \bullet]$.

Changes in size structure and taxonomic composition of plankton may also alter or disrupt food chains [23]. There are formidable challenges in constructing and comparing integrated marine ecosystem models; however, the skills and tools for harmonising such efforts are advancing rapidly, driven by better process understanding, improved data availability and greater computing power [24, 25••]. Uncertainty in future projections arises from three main sources: (i) scenario uncertainty (due to barely foreseeable political, social and economic pathways affecting future greenhouse gas emissions), (ii) model uncertainty due to inaccuracy and incompleteness of the model that can be compensated to some extent by multi-modelling approaches and (iii) internal variability due to the initial state and internal dynamics of specific regions [26]. The consequences of model uncertainty and internal variability increase when moving from global to regional scales. Since strategies for adaptation are developed and implemented at local, national and regional levels, this is the scale at which detailed and reliable projections are most required [24].

Observations of past trends in primary production and phytoplankton abundance or biomass are very limited; however, a recent reconstruction back to 1890 has been attempted using data on optical transparency from Secchi disk measurements as a measure of chlorophyll (Chl). This suggests a global decline in $\mathrm{Chl}$ in most ocean areas, particularly with increasing distance from land, although in some regions (NE Atlantic, South Pacific), Chl has probably increased [27]. 


\section{Adaptation and Acclimatisation}

Climate variables have direct and indirect effects on individuals, populations and whole ecosystems. A key question that has been the focus of much recent research is how rapidly organisms respond to new environmental conditions (principally changes in temperature, oxygen and $\mathrm{pH}$ ) by acclimatisation, phenotypic response and genetic adaptation [28]. The experimental and field evidence for plastic responses is extensive, but the rates and nature of evolutionary responses are difficult to determine.

In tropical regions where temperatures are stable but populations are close to their thermal maxima, the negative effects of increased temperatures are expected to be rapidly apparent. The ability to acclimatise varies considerably between populations of the same species that have become adapted to different ranges of thermal variability. Long-term acclimatisation ability is not well predicted by short-term thermal metabolic reaction norms [29••]; however, thermal acclimatisation during early life may result in physiological changes that help fish cope with increases in water temperature. This response is likely to vary among species and points to the need to examine such effects at all life history stages [30].

The frequency of the two main haemoglobin alleles of North Atlantic cod has been mapped from samples taken throughout the North Atlantic over the past 50 years. It is related to temperature, with the $\mathrm{HbI}^{1}$ allele more frequent in warmer areas [31]. Increasing temperatures may result in changes in genotype frequencies, but the consequences of this for physiological performance and growth have yet to be established.

\section{Asymptotic Size, Growth, Maturation, Spawning and Natural Mortality}

The mean asymptotic maximum size of fish at a particular location is affected by temperature in two ways. (i) Warm water species on average have smaller asymptotic sizes than cooler water species, and increasing temperatures over recent decades have caused species to track their thermal preferenda in a generally poleward direction $[17,32 \bullet \bullet, 33]$. (ii) Temperature- and oxygen-induced physiological changes are expected to result in smaller asymptotic sizes of individual species (Bergmann's rule [34]) and smaller size at maturation [35]. Together, these are expected to cause the mean asymptotic maximum size of the entire fish assemblage in an area to decline by $14-24 \%$ under a high-greenhouse gas emission scenario [36]; however, this is not the same as a reduction in fish productivity, since growth rates and other factors affecting productivity will also change as temperature increases [37]. There are in any case a number of reasons for questioning whether the rate of decline in mean asymptotic maximum size will be as great as 14-24\% [1], and the consequences in terms of productivity are not clear. Northern, colder stocks of sole (Solea solea) had smaller asymptotic size than warm water stocks, an apparent example of countergradient variation that contradicts Bergmann's rule [38••]. Timing of spawning in sole is also influenced by temperature changes [39], which raises concern that phenological changes may result in mismatch between early life stages of fish and their planktonic food supply, hence leading to lower recruitment.

An analysis of $20 \mathrm{~N}$ Atlantic cod populations confirmed that warmer temperatures lead to faster individual growth, earlier maturation and higher natural mortality. Populations in warmer regions can sustain higher levels of exploitation than those in cooler regions; fishery management targets such as maximum sustainable yield are unlikely to remain static under climate change [40].

\section{Recruitment}

Climate change is expected to affect fish populations in a number of ways that have consequences for sustainable harvesting strategies. Two of the main issues that have been the subject of recent research on sub-Arctic stocks are impacts on recruitment and spatial dynamics [41]. An analysis of 38 North Atlantic stocks used linear and non-linear stationary and non-stationary models [42]. Significant effects of temperature on recruitment were detected in all six North Atlantic herring stocks, with increasing temperature having positive effects on cold water stocks. Four plaice stocks in the middle of their thermal range showed negative effects with increasing temperature. Non-stationary (threshold) models gave better fits than linear or non-linear stationary models, indicating that abrupt (regime) shifts may be common. Changes in the intercept of non-linear stationary models suggest that pre-recruit mortality varies over time. Contrary to expectations, no effect of mean age of spawners on recruitment success was detected in this case (but see [43••]). Recruitment of cod in the Kattegat also seemed best explained by a threshold model [44].

Simulation of the effects of environmental variability in juvenile cod production indicates that higher variability entails reduced resilience and greater uncertainty in recovery time [45]. However, if, as indicated above, recruitment processes are non-stationary, then the use of deviations from a stationary stock-recruit relationship, as a measure of effects of environmental variability, may be misleading.

\section{Spatial Dynamics}

Distributions of fish are being altered by climate change and also by fishing pressure, but the fishery management consequences of such spatial changes that affect population structure, sustainable harvesting, resilience and response to climate 
are rarely considered [46]. Spatial structure can be described and aggregated using concepts of sympatry, metapopulation and panmixia and arises because of spatial variability in the physical and biological environment, intra- and interspecific interactions and individual behavioural responses. The consequences of loss of spatial structure include altered demographics and loss of genetic variability and population connectivity, all of which are of considerable fishery management concern, particularly during a period of climate change. The recent spatial expansion and increase in abundance of the anchovy population in the North Sea provided an opportunity to determine whether this was due to migration of populations from warmer areas to the south of the North Sea. Connectivity studies, using genetics, transport modelling and survey time series analysis, indicate that the North Sea anchovy population is separate from those further south and that the recent increase is due to population growth and expansion of a relict North Sea population, not migration $[47 \bullet \bullet]$.

The North Sea is in several ways ideal for relating longterm distribution changes to environmental variability and climate change. It has undergone several cycles of warming and cooling during the past century, driven by regional climate factors (the Atlantic Multidecadal Oscillation) and global warming trends, that have resulted in a rate of warming since the mid 1980s that is among the highest in the world oceans. An analysis of 100 years of detailed, spatially and temporally resolved catch records for North Sea plaice, sole and cod from commercial fisheries and research surveys shows a complex pattern of distributional change related to both temperature change and fishing [48, 49••]. Spatially and temporally resolved data on North Sea cod, plankton abundance and sea surface temperature also allow a detailed analysis of trends in cod recruitment since 1973 and the spatial changes that have accompanied this [50, 51].

A comparison of three species distribution models for this area shows that all have strengths and shortcomings, dependent on their underlying structure and assumptions, and a multi-model approach is therefore recommended [52••]. Reliable detection of climate impacts requires three elements: (1) some prior expectation of the effect of climate change on a particular biological variable (e.g. change in distribution, phenology), (2) good observational data of the variable in question and (3) careful statistical analysis to test whether the observed change is consistent with expectation or not. The actual performance of 208 published studies of climate impacts comprising 1735 biological time series, in relation to these three elements, was used to suggest how the scientific methodology for detecting effects could be improved [53・•].
Table 1 Papers on regional impacts of climate change on fisheries

\begin{tabular}{lll}
\hline Region & Subject & Ref. \\
\hline Arctic & Overview of marine harvesting in a warmer Arctic & {$[54]$} \\
& Impacts on human communities in NW Alaska & {$[55]$} \\
Australia & Management implications for Torres Strait lobster fishery & {$[56]$} \\
& Environment information to enhance decision-making & {$[57 \bullet \cdot]$} \\
& Impacts on fisheries and users & {$[58 \bullet \bullet$} \\
Baltic Sea & Adaptation in resource industries & {$[59]$} \\
& Detection of regime shifts to aid management & {$[60]$} \\
Barents Sea & Dynamic downscaling to model impacts on fisheries & {$[61]$} \\
California & Climate change positively reinforces fishery management in & {$[62]$} \\
& recent recovery of cod stock & {$[63]$} \\
Including environmental variability in management & {$[64 \bullet \cdot]$} \\
South America & Climate forcing and anchovy-sardine fluctuations & {$[65]$} \\
Mediterranean & Assessing non-stationarity in atmosphere-environment interactions & {$[66]$} \\
NE USA & Climate and economic drivers exacerbate stock depletion & {$[67]$} \\
Pacific & Role of climate in shaping fishery landings & {$[68]$} \\
& Human responses and feedbacks & {$[69]$} \\
West Africa & Habitat shifts of top predators & {$[70 \bullet \cdot]$} \\
North Sea, UK and Irish waters & Projecting skipjack tuna distribution and landings & {$[71]$} \\
& Science-management partnership for adaptation in fisheries & {$[72]$} \\
& Review of impacts on marine fish and shellfish & {$[73 \bullet \bullet$} \\
& Socioeconomic impact of range shifts & {$[74 \bullet \cdot]$} \\
& Fishery economics, food, nutritional security & {$[75]$} \\
& Impact of coral bleaching on fisheries and livelihoods & {$[76]$} \\
& Social and ecological vulnerability to reef bleaching & {$[77]$} \\
\hline
\end{tabular}




\section{Regional Impacts of Climate}

Limitations of space preclude a comprehensive review of studies of regional and smaller scale impacts of climate on fisheries. Selected examples (Table 1) give an idea of ongoing work, which in many cases spans from analyses of physical and biological impacts of climate through to include economic, social and adaptation aspects.

\section{Fisheries in Relation to Global Economic and Food Security Issues}

Fisheries globally are under pressure from many factors other than climate change, and these often make the detection of climate impacts more difficult. Nevertheless, in spite of gaps in our understanding, the need for improvements in fishery management and for adaptation to climate-driven changes that are already happening is very clear [78-80]. The demand for increasing fish (from aquaculture as well as capture fisheries) to meet global food requirements over the next 30-40 years can probably be met provided that fisheries are well managed and that the animal feed industry reduces its reliance on fishmeal [81••].

\section{Conclusions}

Projections of future fishery yields are based on newly developed, complex, coupled models of ocean dynamics, biogeochemistry, lower trophic levels and fish populations and either do not include or are only beginning to include processes that may be important, such as ocean acidification, decreasing oxygen, trophic disruption and coastal and shelf sea processes. The Fifth IPCC Report expresses high confidence that mid- and high-latitude fish catch potential will increase by 2050 and medium confidence that low-latitude catch potential will decline, but given the structural limitations of the models, this level of confidence seems unwarranted.

Model development, intercomparison and testing are progressing quickly, as is the investigation of processes, including physiological and population responses to temperature, acidification and oxygen. The collation of existing records and mining of data from old records and preserved material have resulted in greatly improved time series. Finally, detailed work on impacts of climate on fisheries is mainly undertaken at regional and local levels, since these are the scales at which adaptation by fishing enterprises and fishery management takes place. Global forecasts of the effect of climate change on fisheries may have only limited value in helping fisheries to adapt to climate change.

Conflicts of Interest There were no conflicts of interest.

\section{References}

Papers of particular interest, published recently, have been highlighted as:

•- Of major importance

1. Brander K, Neuheimer A, Andersen KH, Hartvig M. Overconfidence in model projections. ICES J Mar Sci. 2013;70:1065-8.

2. Cheung WWL et al. Large-scale redistribution of maximum fisheries catch potential in the global ocean under climate change. Glob Chang Biol. 2010;16:24-35.

3. $\bullet$ Evans K, et al. When $1+1$ can be $>2$ : uncertainties compound when simulating climate, fisheries and marine ecosystems. Deep Sea Res. Part II top. Stud Oceanogr. 2014. Explains major uncertainties in coupled model systems and cautions against overconfidence.

4. Brown CJ, Fulton EA, Possingham HP, Richardson AJ. How long can fisheries management delay action in response to ecosystem and climate change? Ecol Appl. 2012;22:298-310.

5. Punt AE et al. Fisheries management under climate and environmental uncertainty: control rules and performance simulation. ICES J Mar Sci. 2013;71:2208-20.

$6 . \bullet$ Cheung WWL, Dunne J, Sarmiento JL, Pauly D. Integrating ecophysiology and plankton dynamics into projected maximum fisheries catch potential under climate change in the Northeast Atlantic. ICES J Mar Sci. 2011;68:1008-18. Ocean acidification, deoxygenation and phytoplankton community structure may reduce fish catch potential by 30-40\%.

7. Kearney KA, Stock C, Aydin K, Sarmiento JL. Coupling planktonic ecosystem and fisheries food web models for a pelagic ecosystem: description and validation for the subarctic Pacific. Ecol Model. 2012;237-238:43-62.

8. Niiranen $\mathrm{S}$ et al. Combined effects of global climate change and regional ecosystem drivers on an exploited marine food web. Glob Chang Biol. 2013;19:3327-42.

9. Mackinson S. Combined analyses reveal environmentally driven changes in the North Sea ecosystem and raise questions regarding what makes an ecosystem model's performance credible? Can J Fish Aquat Sci. 2014;71:31-46.

$10 . \bullet$ Blanchard JL et al. Potential consequences of climate change for primary production and fish production in large marine ecosystems. Philos Trans R Soc Lond B Biol Sci. 2012;367:2979-89. Use sizebased food web to project effects of climate change on fish biomass and production in 11 large marine ecosystems.

$11 . \bullet$ Barange $\mathrm{M}$ et al. Impacts of climate change on marine ecosystem production in societies dependent on fisheries. Nat Clim Chang. 2014;4:211-6. Global demand in 2050 can be met by aquaculture and wild fisheries given effective management and distribution.

12. Doney $\mathrm{SC}$ et al. Climate change impacts on marine ecosystems. Ann Rev Mar Sci. 2012;4:11-37.

13. Wittmann AC, Pörtner H. Sensitivities of extant animal taxa to ocean acidification. Nat Clim Chang. 2013;3:995-1001.

14. $\bullet$ Hollowed AB et al. Projected impacts of climate change on marine fish and fisheries. ICES J Mar Sci. 2013;70:1023-37. Wide ranging review that identifies 8 research foci to improve projections of climate impacts.

15. Hollowed AB, Curchitser EN, Stock CA, Zhang CI. Trade-offs associated with different modeling approaches for assessment of fish and shellfish responses to climate change. Clim Chang. 2012;119:111-29.

16. Burrows MT et al. The pace of shifting climate in marine and terrestrial ecosystems. Science. 2011;334:652-5.

17. Burrows MT et al. Geographical limits to species-range shifts are suggested by climate velocity. Nature. 2014;507:492-5. 
18. • Poloczanska ES et al. Global imprint of climate change on marine life. Nat Clim Chang. 2013;3:919-25. Largest assembly and analysis of global impacts of climate on marine biota.

19. Sunday JM, Bates AE, Dulvy NK. Thermal tolerance and the global redistribution of animals. Nat Clim Chang. 2012;2:1-5.

20. Cheung WWL, Watson R, Pauly D. Signature of ocean warming in global fisheries catch. Nature. 2013;497:365-8.

21. $\bullet$ Mitra A et al. Bridging the gap between marine biogeochemical and fisheries sciences; configuring the zooplankton link. Prog Oceanogr. 2014;129:176-99. Reliability of physics-to-fish models is compromised because zooplankton are underrepresented or ignored.

22. Chust $\mathrm{G}$ et al. Biomass changes and trophic amplification of plankton in a warmer ocean. Glob Chang Biol. 2014;20:2124-39.

23. Schlüter MH, Kraberg A, Wiltshire KH. Long-term changes in the seasonality of selected diatoms related to grazers and environmental conditions. J Sea Res. 2012;67:91-7.

24. Allen JI et al. Marine ecosystem models for earth systems applications: the MarQUEST experience. J Mar Syst. 2010;81:19-33.

$25 . \bullet$ Holt $\mathrm{J}$ et al. Challenges in integrative approaches to modelling the marine ecosystems of the North Atlantic: physics to fish and coasts to ocean. Prog Oceanogr. 2014. doi:10.1016/j.pocean.2014.04.024. Detailed review of integrative modelling from physics to fish and its application in relation to ecosystem based management.

26. Holt J. Oceanic controls on the primary production of the northwest European continental shelf: model experiments under recent past conditions and a potential future scenario. 2012.

27. Boyce DG, Dowd M, Lewis MR, Worm B. Estimating global chlorophyll changes over the past century. Prog Oceanogr. 2014;122: 163-73.

28. Crozier LG, Hutchings JA. Plastic and evolutionary responses to climate change in fish. Evol Appl. 2014;7:68-87.

29. • Donelson JM, Munday PL. Thermal sensitivity does not determine acclimation capacity for a tropical reef fish. J Anim Ecol. 2012;81: 1126-31. Thermal acclimation varies greatly between populations and will affect response to climate change.

30. Grenchik MK, Donelson JM, Munday PL. Evidence for developmental thermal acclimation in the damselfish, Pomacentrus moluccensis. Coral Reefs. 2012;32:85-90.

31. Ross SD, Behrens JW, Brander K, Methling C, Mork J. Haemoglobin genotypes in cod (Gadus morhua L): their geographic distribution and physiological significance. Comp Biochem Physiol A Mol Integr Physiol. 2013;166:158-68.

32.• Pinsky ML, Worm B, Fogarty MJ, Sarmiento JL, Pinsky ML, Worm B, et al. Marine taxa track local climate velocities. Science. 2013;341:1239-42. Distribution shifts in marine species track local thermal climate velocities.

33. MacKenzie BR, Payne MR, Boje J, Høyer JL, Siegstad H. A cascade of warming impacts brings bluefin tuna to Greenland waters. Glob Chang Biol. 2014;20:2484-91.

34. Baudron AR, Needle CL, Rijnsdorp AD, Marshall CT. Warming temperatures and smaller body sizes: synchronous changes in growth of North Sea fishes. Glob Chang Biol. 2014;20:1023-31.

35. Forster J, Hirst AG, Atkinson D. Warming-induced reductions in body size are greater in aquatic than terrestrial species. Proc Natl Acad Sci U S A. 2012;109:19310-4

36. Cheung WWL et al. Shrinking of fishes exacerbates impacts of global ocean changes on marine ecosystems. Nat Clim Chang. 2012;3:254-8

37. Neuheimer AB, Grønkjaer P. Climate effects on size-at-age: growth in warming waters compensates for earlier maturity in an exploited marine fish. Glob Chang Biol. 2012;18:1812-22.

$38 . \bullet$ Mollet FM et al. Spatial variation in growth, maturation schedules and reproductive investment of female sole Solea solea in the Northeast Atlantic. J Sea Res. 2013;84:109-21. Temperature related spatial variation in sole contradicts Bergmann's rule and may be evidence of strong countergradient thermal adaptation.

39. Fincham JI, Rijnsdorp AD, Engelhard GH. Shifts in the timing of spawning in sole linked to warming sea temperatures. J Sea Res. 2013;75:69-76.

40. Wang $\mathrm{H}$, et al. Effects of temperature on life history set the sensitivity to fishing in Atlantic cod Gadus morhua. Mar Ecol Prog Ser. 2014.

41. Durant J, Ottersen G, Stenseth N. Harvested fish stocks in a changing environment. Mar Ecol Prog Ser. 2013;480:199-203.

42. Ottersen $\mathrm{G}$ et al. Temporal shifts in recruitment dynamics of North Atlantic fish stocks: effects of spawning stock and temperature. Mar Ecol Prog Ser. 2013;480:205-25.

$43 . \bullet$ Durant $\mathrm{J}$ et al. Population growth across heterogeneous environments: effects of harvesting and age structure. Mar Ecol Prog Ser. 2013;480:277-87. Introduction to a group of 5 major papers on harvesting fish stocks in a changing environment.

44. Lindegren M, Eero M. Threshold-dependent climate effects and high mortality limit recruitment and recovery of the Kattegat cod. Mar Ecol Prog Ser. 2013;490:223-32.

45. Kuparinen A, Keith DM, Hutchings JA. Increased environmentally driven recruitment variability decreases resilience to fishing and increases uncertainty of recovery. ICES J Mar Sci. 2014;71:150714.

46. Ciannelli L et al. Theory, consequences and evidence of eroding population spatial structure in harvested marine fishes: a review. Mar Ecol Prog Ser. 2013;480:227-43.

$47 . \bullet$ Petitgas $\mathrm{P}$ et al. Anchovy population expansion in the North Sea. Mar Ecol Prog Ser. 2012;444:1-13. Expansion of anchovy population resulted from a local remnant stock, not immigration.

48. Engelhard GH, Pinnegar JK, Kell LT, Rijnsdorp AD. Nine decades of North Sea sole and plaice distribution. 2011;68:1090-1104.

49. • Engelhard GH, Righton DA, Pinnegar JK. Climate change and fishing: a century of shifting distribution in North Sea cod. Glob Chang Biol. 2014;20:2473-83. Shifts in North Sea cod distribution since 1913 are caused by fishing as well as climate change.

50. Nicolas D, Rochette S, Llope M, Licandro P. Spatio-temporal variability of the North Sea cod recruitment in relation to temperature and zooplankton. PLoS One. 2014;9:e88447.

51. Hjermann D, Fisher J, Rouyer T, Frank K, Stenseth N. Spatial analysis of North Sea cod recruitment: concurrent effects of changes in spawning stock biomass, temperature and herring abundance. Mar Ecol Prog Ser. 2013;480:263-75.

$52 . \bullet$ Jones MC, Dye SR, Pinnegar JK, Warren R, Cheung WWL. Modelling commercial fish distributions: prediction and assessment using different approaches. Ecol Model. 2012;225:133-45. Distribution shifts should be modelled using several approaches to account for biases.

53. $\bullet$ O'Connor MI et al. Strengthening confidence in climate change impact science. Glob Ecol Biogeogr. 2015;24(1):64-76. Attribution of observed biological change to climate requires clear prior expectations, appropriate data and well designed statistical testing.

54. Haug T, Aschan M, Hoel AH, Johansen T, Sundet JH. Introduction: marine harvesting in the Arctic. ICES J Mar Sci. 2014;71:1932-3.

55. Moerlein KJ, Carothers C. Total environment of change: impacts of climate change and social transitions on subsistence fisheries in Northwest Alaska. Ecol Soc. 2012;17.

56. Norman-López A et al. Linking physiological, population and socio-economic assessments of climate-change impacts on fisheries. Fish Res. 2013;148:18-26.

57. • Spillman CM, Hobday AJ. Dynamical seasonal ocean forecasts to aid salmon farm management in a climate hotspot. Clim Risk Manag. 2014;1:25-38. Working together with fishing enterprises to develop forecast of local conditions that will help them adapt to climate. 
58. • Van Putten IE, Metcalf S, Frusher S, Marshall N, Tull M. Fishing for the impacts of climate change in the marine sector: a case. Int J Clim Chang Strateg Manag. 2014;6. Understanding how local communities and enterprises can adapt to climate with examples from Australian fisheries.

59. Hodgkinson JH, Hobday AJ, Pinkard EA. Climate adaptation in Australia's resource-extraction industries: ready or not? Reg Environ Chang. 2014;14:1663-78.

60. Lindegren $\mathrm{M}$ et al. Early detection of ecosystem regime shifts: a multiple method evaluation for management application. PLoS One. 2012;7:e38410.

61. Mackenzie BR et al. Impact of climate change on fish population dynamics in the Baltic Sea: a dynamical downscaling investigation. Ambio. 2012;41:626-36.

62. Kjesbu OS et al. Synergies between climate and management for Atlantic cod fisheries at high latitudes. Proc Natl Acad Sci U S A. 2014;111:3478-83.

63. Lindegren M, Checkley DM, Quinn T. Temperature dependence of Pacific sardine (Sardinops sagax) recruitment in the California Current ecosystem revisited and revised. Can J Fish Aquat Sci. 2013;70:245-52.

64. • Lindegren M, Checkley DM, Rouyer T, MacCall AD, Stenseth NC. Climate, fishing, and fluctuations of sardine and anchovy in the California Current. Proc Natl Acad Sci U S A. 2013;110:136727. Density dependence and climate account for sardine-anchovy fluctuations since 1661.

65. Sydeman WJ, Santora JA, Thompson SA, Marinovic B, Di Lorenzo E. Increasing variance in North Pacific climate relates to unprecedented ecosystem variability off California. Glob Chang Biol. 2013;19:1662-75.

66. Defeo $\mathrm{O}$ et al. Impacts of climate variability on Latin American small-scale fisheries. Ecol Soc. 2013;18.

67. Tzanatos E, Raitsos DE, Triantafyllou G, Somarakis S, Tsonis AA. Indications of a climate effect on Mediterranean fisheries. Clim Chang. 2014;122:41-54.

68. Pinsky ML, Fogarty M. Lagged social-ecological responses to climate and range shifts in fisheries. Clim Chang. 2012;115:883-91.

69. Hazen EL et al. Predicted habitat shifts of Pacific top predators in a changing climate. Nat Clim Chang. 2012;3:234-8.

70. • Lehodey P, Senina I, Calmettes B, Hampton J, Nicol S. Modelling the impact of climate change on Pacific skipjack tuna population and fisheries. Clim Chang. 2012;119:95-109. Coupled physics to fish model used to project impact of climate on skipjack tuna.

71. Salinger MJ et al. Climate and oceanic fisheries: recent observations and projections and future needs. Clim Chang. 2013;119:21321.

72. Cheung WWL, Pinnegar J, Merino G, Jones MC, Barange M. Review of climate change impacts on marine fisheries in the UK and Ireland. Aquat Conserv Mar Freshw Ecosyst. 2012;22: 368-88.

73. $\bullet$ Heath MR et al. Review of climate change impacts on marine fish and shellfish around the UK and Ireland. Aquat Conserv Mar Freshw Ecosyst. 2012;22:337-67. Detailed review of regional climate impacts and future expectations that shows the limitations of climate envelope models.

74. • Jones MC, Dye SR, Pinnegar JK, Warren R, Cheung WWL. Using scenarios to project the changing profitability of fisheries under climate change. Fish Fish. 2014. doi:10.1111/faf.12081. Projecting economic impacts of climate and implications for policy and management.

75. Lam V, Cheung W, Swartz W, Sumaila U. Climate change impacts on fisheries in West Africa: implications for economic, food and nutritional security. Afr J Mar Sci. 2012;34:103-17.

76. Cinner JE et al. Vulnerability of coastal communities to key impacts of climate change on coral reef fisheries. Glob Environ Chang. 2012;22:12-20.

77. Cinner JE et al. Evaluating social and ecological vulnerability of coral reef fisheries to climate change. PLoS One. 2013;8:e74321.

78. Sumaila UR, Cheung WWL, Lam VWY, Pauly D, Herrick S. Climate change impacts on the biophysics and economics of world fisheries. Nat Clim Chang. 2011;1:449-56.

79. Ruckelshaus $M$ et al. Securing ocean benefits for society in the face of climate change. Mar Policy. 2013;40:154-9.

80. Haynie AC, Pfeiffer L. Why economics matters for understanding the effects of climate change on fisheries. ICES J Mar Sci. 2012;69: 1160-7.

81. $\bullet$ Merino $G$ et al. Can marine fisheries and aquaculture meet fish demand from a growing human population in a changing climate? Glob Environ Chang. 2012;22:795-806. Yes, but only if fish resources are managed sustainably and the animal feeds industry reduces its reliance on wild fish. 